\title{
Uncertainty in Material Flow Analysis Indicators at different spatial levels
}

\author{
João Patrício ${ }^{1 *}$, Yuliya Kalmykova ${ }^{1}$, Leonardo Rosado ${ }^{1}$ \\ ${ }^{1}$ Department of Civil and Environmental Engineering, Chalmers University of Technology, 412 96, \\ Gothenburg, Sweden;
}

\begin{abstract}
Material Flow Analysis (MFA) is a tool for research and decision support in environmental policy and management. In order to promote the use of MFA at different spatial scales, a quantification of the uncertainty in nation-wide, regional and urban MFA methodologies is provided. In particular, the impact of the input data quality on the main MFA indicators is analysed and the sources and extent of uncertainties for different spatial scales are listed. The types, origin and extent of the errors are described in detail and several imputation methods are explained and evaluated. By introducing a novel approach to account measurement errors in datasets with "very few details on the measurement errors" this article aims at contributing to the development of a standardized method to account for the uncertainty in MFA studies. This study uses the time series of MFA data for 1996-2011 at three spatial scales - nation-wide (Sweden), regional (the Stockholm Region) and metropolitan (Stockholm, Gothenburg and Malmo) - to determine how propagation of measurement errors affects the MFA results. The following MFA indicators were studied: Direct Material Input (DMI), Domestic Processed Output (DPO) and Domestic Material Consumption (DMC). Generally, availability decreased as the spatial scale was lowered, while data errors increased. In the specific case of Sweden, the data on freight transport by rail and on waste produced by economic activities at the regional and metropolitan level should be improved.
\end{abstract}

\section{$<$ heading level $1>$ Introduction}

Material Flow Analysis (MFA) is a method commonly used in the Industrial Ecology research field in particular for socio-economic metabolism studies. During the last decade, the use of this method as a scientific support tool for environmental policy and management has increased due to the harmonization of the MFA concepts and methods by the Central Statistical Office of the European Communities (Eurostat) and the Organization for Economic Co-operation and Development (OECD) (Eurostat 2001; OECD 2008). In particular, the Economy-Wide Material Flow Analysis Method (Economy-wide MFA) was developed by Eurostat in order to enable the comparison of MFA indicators for different countries as well as for different timeperiods (Eurostat 2001). Since then, the methodology has been used by the European states on a regular basis. In addition, MFA is increasingly being used not only at the national level, but also at lower administrative and spatial scales (Kennedy et al. 2011; Kalmykova et al. 2014). As an example the economy-wide MFA was adapted for analysis of urban areas, the so called Urban Metabolism Analyst (UMAn), where comparisons between imputations and real available data 
for selected products were made, and the differences accounted in closing the material balance to evaluate the model consistency (Rosado et al. 2014a).

Several tools that can assess uncertainty in MFA case studies. Additionally, they already exist. There has been research conducted to evaluate the uncertainty in MFA studies. A good example is the Mathematical Material Flow Analysis methodology developed by Baccini and Bader (1996). The methodology combines the conventional MFA with modern concepts of mathematical modelling, making possible to handle uncertainties of data and to simulate the behaviour of the system under various conditions. The methodology has been applied to many case studies in different fields, especially in dynamic MFA.

It is known that MFA results are influenced by the method used and the quality of the collected data (Fischer-Kowalski et al. 2011; Statistics Austria 2009). Although it is often stated that uncertainty analysis should be included in all descriptive MFA case studies [quantification of material balance in a specific region], the majority of studies do not address the measurement errors associated with the databases, or with the applied model (e.g.: Hammer et al. 2003a; Cañellas et al. 2004; Browne et al. 2011). When addressed, these errors are often commented on in qualitative terms or as an expert judgment. For instance, in the Economywide MFA for Sweden (Carlsson et al. 2006), Foreign Trade Statistics were declared to be of 'good quality' and a study from Finland (Statistics Finland 2010) stated that 'data on domestic flows and exports can be considered very reliable' and 'generally DMI [Domestic Material Input] and DMC [Domestic Material Consumption] are regarded as good indicators, as the data behind them is quite reliable'. One example of a study that includes a quantitative analysis of the MFA reliability is the Investigation into Domestic Extraction (DE) compilation consistency between multi-national studies (Fischer-Kowalski et al. 2011). The results for DE, and the main material groups including 27 EU-countries in 2000, by different authors were cross-compared and standard deviations below $10 \%$ of global means were found. In contrast, data measurement errors quantification has become a usual practice in Substance Flow Analysis studies [an MFA focused on selected substances] for both descriptive and exploratory studies. Example of these studies can be found since 1990's (e.g.: Hansen and Lassen 1998) as well as in other more recent studies performed for heavy metals and nutrients balances (e.g.: Danius and Burström 2001; Hedbrant and Sörne 2001; Gottschalk et al. 2010; Kalmykova et al. 2012).

In 2014, Laner and colleges reviewed and evaluated the practice of uncertainty analysis for both descriptive and exploratory MFA and SFA. According to the authors, mathematical simpler concepts focusing on data uncertainty are well suited for descriptive MFA. Analysis of uncertainty in the data should be an integral part of every MFA, so that suggested conclusions may be examined and the significance of the differences in the obtained results taken into account by users and decision-makers. Furthermore, the methodology, data sources and assumptions generally described as part of MFA studies should be accompanied by a description of the uncertainty associated with the methodology, data sources and assumptions (Danius 2002; Huybrechts et al. 1996; Lindqvist 2002).

This article provides a quantitative analysis of the measurement errors in the MFA input empirical data, at 3 different spatial levels. The uncertainties in the results of MFA on the 
country-wide, regional and metropolitan scales are quantified using a time series of MFA studies for 1996-2011, for Sweden, the Stockholm Region and three metropolitan areas. The objectives of this research are to: i) analyse and assess in quantitative terms the uncertainty of the datasets used from economy-wide to urban MFA; ii) describe differences in the quality of the databases used at different scales; iii) evaluate the impact of the quality of datasets on the main MFA indicators; and iv) quantify the uncertainties for the main MFA indicators.

This article intents to be a contribution to the development of a generic method that reconciles different sources of uncertainty from different databases typically used in MFA studies. A method that provides a general idea of the uncertainty in MFA studies will allow a quick assessment of the results, and support comparative analysis between different case studies. The model can also be used in several other industrial ecology fields that traditional use large and diverse sets of data, as for instance LCA, physical and monetary input-output tables.

\section{<heading level $1>$ Method}

\section{$<$ heading level 2> Material Flow Analysis}

Material flow analysis was performed at three spatial scales: country scale (Sweden), regional scale (Stockholm Region) and metropolitan area scale (Stockholm, Gothenburg and Malmo) (Kalmykova et al. 2014). At country level, the economy-wide MFA method was applied, while the UMAn method was used for the region and metropolitan areas. The system boundaries were defined according with the economy-wide MFA (for details on the MFA boundaries, see chapter 3.2 of economy-wide MFA). Indirect flows, also referred to as 'hidden flows' or 'embodied materials', were not included. The impact of data quality on the following main MFA indicators was investigated:

- $\quad$ Direct Material Input (DMI): imports plus used domestic extraction (excavated raw material, harvested biomass). Input indicator.

- $\quad$ Domestic Processed Output (DPO): emissions to air, landfilled wastes from economic activities and households, sludge from wastewater treatment and dissipative flows (solid part). Output indicator.

- Domestic Material Consumption (DMC): DMI minus exports. Consumption indicator.

- Net Addition to Stock (NAS) - DMI minus exports and DPO. Consumption indicator.

A summary of the data requirements and sources for the MFA at country, regional and metropolitan area level is available in table 1. The transport data provides information on the imports and exports of goods. At the country scale, this data corresponds to all the international imports and exports of goods, traditionally defined as international trade data. For regions and metropolitan areas, data on the intranational [national transport] imports and export of goods by means of transport had to be collected (water, road, rail and air). The domestic extraction accounts for the extraction of materials in the area, such as crop production, bulk materials extraction or metallic minerals extraction. The following equation shows an example on how the DMI indicator was calculated for Stockholm Region and for Sweden: 
Equation 1:

$$
\begin{gathered}
\text { DMI Stockholm Region } \\
\begin{array}{r}
\text { with } r=1,2 \text { national transport and international transport }, m=1, \ldots, 4 \text { transport modes, } p \\
=1,2 \ldots n \text { types of domestic extration }
\end{array} \\
\qquad \sum_{m=1}^{4} \text { IMPORTS }+\sum_{\text {Sweden }}^{n} \text { Domestic Extraction } \\
\sum_{r=1}^{1} \sum_{m=1}^{4} I M P O R T S+\sum_{p=1}^{n} \text { Domestic Extraction }
\end{gathered}
$$

with $r=1$ international transport $m=1, \ldots, 4$ transport modes, $p=1,2 \ldots n$ types of domestic extration

In order to close the material balance, data on the Outputs to Nature material flow indicator (DPO) is necessary, where air emissions, urban waste, economic activities waste (industrial Waste) and dissipative flows are included. As the inputs of air were not taken into account, the air emissions weight only considers the mass of Carbon in the Carbon Dioxide. Finally, the auxiliary data (table 1 ) is used to do imputations [process of replacing missing data] (Hair et al. 1998). 
Table 1 -Main Data inputs and Sources Collected

\begin{tabular}{|c|c|c|c|c|c|c|c|c|}
\hline \multirow{2}{*}{ Data Inputs } & \multirow{2}{*}{$\begin{array}{c}\text { MFA } \\
\text { Indicator }\end{array}$} & \multirow{2}{*}{ Purpose } & \multicolumn{3}{|c|}{$\begin{array}{c}\text { Spatial } \\
\text { Resolution } \\
\text { Data } \\
\text { Availability }\end{array}$} & \multirow{2}{*}{ Source } & \multirow[b]{2}{*}{ Other Information } & \multirow{2}{*}{$\begin{array}{l}\text { Uncertainty } \\
\text { Errors }\end{array}$} \\
\hline & & & 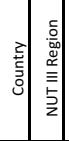 & 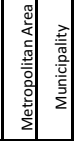 & 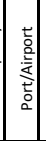 & & & \\
\hline $\begin{array}{l}\text { International } \\
\text { Statistics (ITS) }\end{array}$ & $\begin{array}{l}\text { Inputs / } \\
\text { Outputs }\end{array}$ & $\begin{array}{l}\text { Imports and Exports - Used for country level } \\
\text { accounting }\end{array}$ & & & & Statistics Sweden (SCB) & $\begin{array}{l}\text { Data is available online, both in Eurostat } \\
\text { and in the SCB website. But, due to } \\
\text { confidential values, a special agreement } \\
\text { had to be signed with SCB to have access to } \\
\text { all data. }\end{array}$ & $\mathrm{C}$ \\
\hline $\begin{array}{ll}\text { Road } & \text { Transport } \\
\text { Statistics } & \end{array}$ & $\begin{array}{l}\text { Inputs / } \\
\text { Outputs }\end{array}$ & $\begin{array}{l}\text { Road Imports and Exports -Used for regional and } \\
\text { metropolitan level accounting }\end{array}$ & & & & $\begin{array}{l}\text { Swedish Transport } \\
\text { Administration; }\end{array}$ & $\begin{array}{l}\text { Public Report: "Lastbilstrafik } 2010- \\
\text { Swedish national and international road } \\
\text { goods transport 2010" }\end{array}$ & A \\
\hline $\begin{array}{l}\text { Water } \\
\text { Statistics }\end{array}$ & $\begin{array}{l}\text { Inputs/ } \\
\text { Outputs }\end{array}$ & $\begin{array}{l}\text { Water Imports and Exports -Used for regional and } \\
\text { metropolitan level accounting }\end{array}$ & & & & $\begin{array}{l}\text { Swedish Transport } \\
\text { Administration }\end{array}$ & $\begin{array}{l}\text { Public Report: "Sjötrafik 2010 - Shipping } \\
\text { goods 2010, Trafikanalys" }\end{array}$ & $\mathrm{C}$ \\
\hline $\begin{array}{ll}\text { Air } & \text { Transport } \\
\text { Statistics } & \\
\end{array}$ & $\begin{array}{l}\text { Inputs / } \\
\text { Outputs }\end{array}$ & $\begin{array}{l}\text { Air Imports and Exports -Used for regional and } \\
\text { metropolitan level accounting }\end{array}$ & & & & Swedish Transport Agency & $\begin{array}{l}\text { Public Report: "Lufffart } 2010 \text { - Civil Aviation } \\
\text { 2010, Trafikanalys" }\end{array}$ & $\mathrm{C}$ \\
\hline $\begin{array}{ll}\text { Rail } & \text { Transport } \\
\text { Statistics } & \\
\end{array}$ & $\begin{array}{l}\text { Inputs / } \\
\text { Outputs }\end{array}$ & $\begin{array}{l}\text { Rail, Road, Water and Air Imports and Exports - } \\
\text { Used for regional and metropolitan level } \\
\text { accounting }\end{array}$ & & & & Eurostat & $\begin{array}{l}\text { Rail transport was only available for } 2010 \\
\text { (Eurostat data). }\end{array}$ & $\mathrm{D}$ \\
\hline $\begin{array}{l}\text { Agricultural } \\
\text { production }\end{array}$ & Inputs & $\begin{array}{l}\text { Crop production, crop residues, fruits and } \\
\text { vegetables, fodder crops, flowers and plants, } \\
\text { nurseries, etc. }\end{array}$ & & & & $\begin{array}{l}\text { SCB / Swedish Board of } \\
\text { Agriculture; Eurostat }\end{array}$ & Public Data available on SCB website & $A, C$ \\
\hline Forestry production & Inputs & Round-wood and fuel-wood extraction & & & & Swedish Forest Agency & $\begin{array}{l}\text { Public Data available on Swedish Forest } \\
\text { Agency website }\end{array}$ & $A, C$ \\
\hline Fisheries & Inputs & Sea and inland fishing & & & & $\begin{array}{l}\text { Swedish Agency for Marine and } \\
\text { Water Management (SwAM) }\end{array}$ & Data made available by SwAM & $\mathrm{D}$ \\
\hline Animal farming & Inputs & Animal populations & & & & SCB & Public Data available on SCB website & $\mathrm{D}$ \\
\hline Fossil Fuels Extraction & Inputs & Fossil fuels extraction & & & & Swedish Geological Survey & Public Data available on SCB website & $\mathrm{C}$ \\
\hline $\begin{array}{lr}\text { Metallic } & \text { and } \\
\text { metallic } & \text { non- } \\
\text { extraction } & \text { Mining } \\
\end{array}$ & Inputs & $\begin{array}{l}\text { Extraction of metallic and non-metallic minerals as } \\
\text { well as bulk materials }\end{array}$ & & & & Swedish Geological Survey & Public Data available on SCB website & $\mathrm{C}$ \\
\hline $\begin{array}{l}\text { Energy production and } \\
\text { consumption }\end{array}$ & Inputs & Energy: primary production and final consumption & & & & Swedish Geological Survey & Public Data available on SCB website & - \\
\hline Municipal wastes & Outputs & $\begin{array}{l}\text { Municipal } \\
\text { Recycling/Reuse/Valorisate } \\
\text { generation/Disposal statistics }\end{array}$ & & & & $\begin{array}{l}\text { Swedish Waste Management } \\
\text { and Recycling association } \\
\text { (Avfall Sverige); }\end{array}$ & Data made available by Avfall Sverige & $B, C$ \\
\hline Industrial wastes & Outputs & $\begin{array}{l}\text { Other than municipal waste generation, } \\
\text { Recycling/Reuse/Valorisation statistics }\end{array}$ & & & & Swedish EPA & Public Data: "Avfall i Sverige 2010" & $A, C$ \\
\hline $\begin{array}{l}\text { Emissions of Carbon } \\
\text { Dioxide }\end{array}$ & Outputs & Air emissions, both fossil fuel and biomass origin & & & & $\begin{array}{l}\text { Regional Development and } \\
\text { Cooperation (RUS); Statistics } \\
\text { Sweden; Swedish EPA }\end{array}$ & Public Data available on RUS website & $A, C$ \\
\hline $\begin{array}{l}\text { Sludge - Waste Water } \\
\text { Treatment }\end{array}$ & Outputs & Sludge (dry weight) from sewage treatment & & & & SCB & $\begin{array}{l}\text { Public Report: "Utsläpp till vatten och } \\
\text { slamproduktion" }\end{array}$ & C \\
\hline Land Area & Auxiliary & Arable land by plantation & & & & SCB & Public Data available on SCB website & - \\
\hline Population & Auxiliary & Population & & & & SCB & Public Data available on SCB website & - \\
\hline Number of Employees & Auxiliary & Number of employees per NACE code & & & & SCB & $\begin{array}{l}\text { Special agreement signed with SCB to have } \\
\text { access to the data }\end{array}$ & - \\
\hline
\end{tabular}

$<$ heading level 2> Data Collection

Data was acquired from official publications and databases of a large array of organizations and institutes. Priority was given to national sources. Whenever possible, data for the region and metropolitan areas was collected at the municipal scale or at the metropolitan area scale. Other data was collected for the higher administrative boundaries available, as it can be seen in table 1. This included for instance NUTS Regions data. In the case of Sweden (NUT I), the Stockholm metropolitan area corresponds to a complete NUT III Region, called the Stockholm Region (see figure 1). The data from NUT III Region can then be used directly for Stockholm Region. However, Malmo metropolitan area is only a part of the NUT III Skane Region and Gothenburg metropolitan area is composed of twelve municipalities within the NUT III Vastra Gotaland Region and one within the NUT III Halland Region. For this reason, when data was only available at NUT III spatial scale, imputations were made for Gothenburg and Malmo metropolitan areas. 


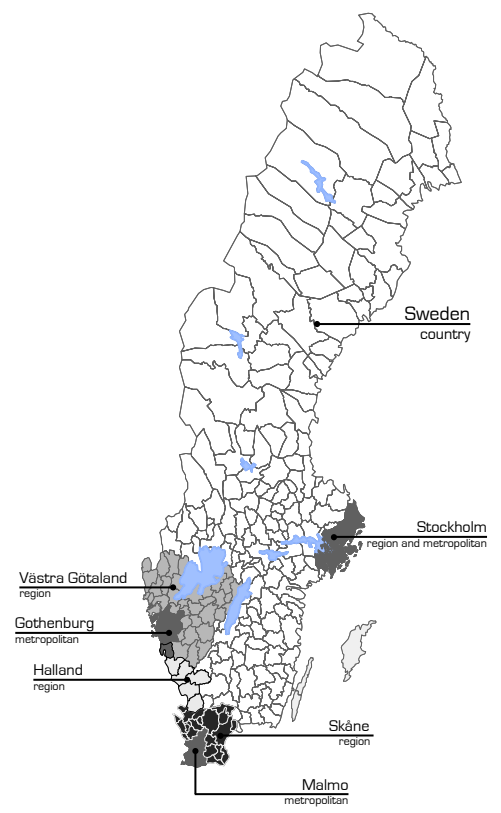

\section{Figure 1 - Spatial scales}

When there was no data available at the smaller spatial scales previously mentioned, the national scale was used to impute the regional and metropolitan scales, as it is described in detail in the next subsection.

\section{<heading level 2> Data Imputations}

In some cases, data was not available at the urban level, requiring that data be imputed from other available, larger, spatial scales. For instance, Agricultural production and Forestry data were only available for the NUT III Regions. For Gothenburg and Malmo the values describing domestic extraction had to be imputed. Two different imputation methods were tested. By the first approach, the number of workers within a specific economic activity in the metropolitan area was put in relation to the data for NUT III and used to impute the different products extracted. By the second approach, the calculations were based on the land area used to grow different types of plants. Whenever this data was not available by type of plantation, mainly for confidentiality reasons, the total land area ratio between the two scales was used. For the imputation of the forestry production, the ratio of woodland was used. The following example (Equation 2) shows how apple production was imputed for Malmo Metropolitan Area.

Equation 2:

Approach 1:

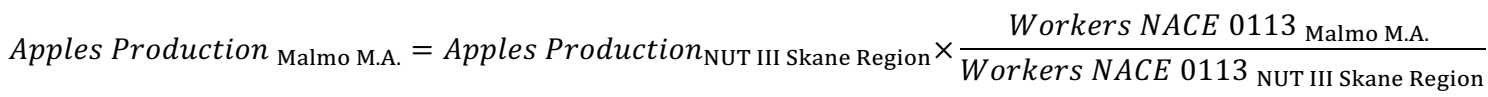
where NACE 0113 represents the Production of fruit and berries economic activity 
Approach 2:

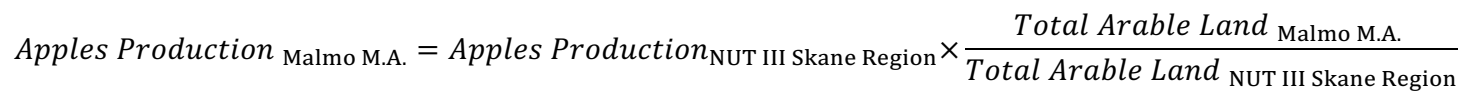

In some cases, and due to the fact that the study was performed for 16 years, gaps of data could be found, mostly on agriculture productions. Therefore and when necessary other data was used, such as land area and production yields. Other option was to interpolate the production using trends, such as the production in adjacent years.

Certain material flow Outputs data had also to be imputed. At the country scale, industrial waste disposal by economic sector (NACE classification) was only available for the years 1998, 2002, 2004, 2006, 2008 and 2010. For instance in 2010 textile sector produced 32 thousand tonnes in Sweden (Naturvårdsverket, 2012). For all other years, amounts were imputed based on the average waste disposed per worker per sector observed in the adjacent years, and the number of workers per economic sector during the imputed year. For region and metropolitan areas, industrial waste was imputed using the country scale data. The imputations were made by allocating a proportion of the country amounts to the area, based on the number of workers within the economic activity in question within the region or metropolitan area divided by the number in the country as a whole (Equation 3 ).

Equation 3:

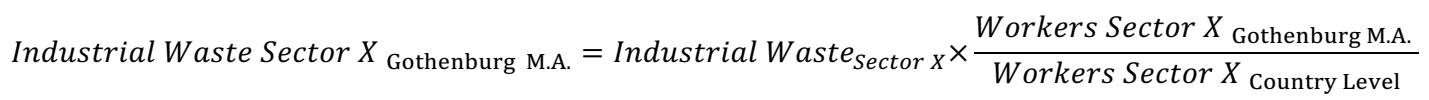

where Sector X represents the Sectors from Economic Activitives

The dissipative flows were also imputed, by multiplying per capita values found for Germany and Austria by the population size (Matthews et al. 2000). Data on $\mathrm{CO}_{2}$ emissions from fossil fuels origin was available at national level for all the years, but it was only available for Regions and Metropolitan Areas for 2000, and from 2005 to 2011. This data was available by sectors. For the other years, data was imputed by multiplying the share of emissions of each sector of the Region in relation with the Country, observed in the adjacent years, by the amount of $\mathrm{CO}_{2}$ emissions available at national Level. The following example shows how $\mathrm{CO}_{2}$ emissions was imputed the derived from energy production for Gothenburg Metropolitan Area in 2004.

Equation 4:

CO2 Emissions from Energy Production Sector in 2005:

Gothenburg M. A.: 3,037,334 tonnes and Sweden: 23,275,460 tonnes

CO2 Emissions from Energy Production in 2004:

Considering that the Emissions for Sweden in $2004=24,351,000$ tonnes,

The imputation for $\mathrm{CO} 2$ emissions for Gothenburg M. A. is given by:

Gothenburg $M . A .=\frac{3,037,334}{23,275,460} \times 24,351,000=3,177,687$ tonnes of CO2

Whenever possible, the methods of imputation were evaluated by applying them to data where values at both spatial scales were available. The differences between the real and 
imputed values were registered, and are shown in Results and Discussion section (Subsection Imputations). Since it was not possible to assess the magnitude of associated measurement errors, and in order to account the uncertainty in the MFA indicators, the maximum differences registered for each imputation was assumed as the uncertainty.

\section{$<$ heading level 2> Different Sources of error in MFA Results}

The MFA may be affected by differences in data originating from different countries, use of different unit operations, different sources, and subjective methodological choices. The standards and procedures for data collection and presentation differ between institutions. This means that it is often not possible to directly compare the measurement errors of similar datasets from different institutions. However, standardization of international data collection contributes to bridging this gap. One example is the international trade statistics, which are collected according to the Eurostat protocols. The types of uncertainty that may be associated with MFA studies (summarized in table 2) have been compiled, and are similar to the ones reported in a study of LCA reliability (Björklund 2002). 


\section{Table 2 - Different types of errors in MFA. Adapted from Björklund}

(2002)

\begin{tabular}{|c|c|c|c|}
\hline Type & Description & Comments & $\begin{array}{l}\text { Uncertainty } \\
\text { Errors }\end{array}$ \\
\hline $\begin{array}{l}\text { Measurement } \\
\text { errors }\end{array}$ & $\begin{array}{l}\text { Errors associated with the } \\
\text { databases needed to conduct the } \\
\text { MFA. }\end{array}$ & $\begin{array}{l}\text { Collected from the institutions } \\
\text { providing the databases. }\end{array}$ & $A, B$ \\
\hline Data Gaps & $\begin{array}{l}\text { Missing values in the databases } \\
\text { due to confidentiality rules or for } \\
\text { other unknown reasons. }\end{array}$ & $\begin{array}{l}\text { An agreement with SCB allowed } \\
\text { access to confidential data. } \\
\text { Missing values were imputed } \\
\text { based on data from previous } \\
\text { years. }\end{array}$ & - \\
\hline $\begin{array}{l}\text { Error due to } \\
\text { choices }\end{array}$ & $\begin{array}{l}\text { Model choice. Despite availability } \\
\text { of the standardized MFA } \\
\text { methodology at country level, } \\
\text { other models may sometimes be } \\
\text { used. Furthermore, at the } \\
\text { regional and metropolitan level, } \\
\text { there is no standard model for } \\
\text { MFA. } \\
\text { Errors due assumptions, } \\
\text { simplification or other choices. }\end{array}$ & $\begin{array}{l}\text { Used the Economy-wide MFA at } \\
\text { country level. At regional and } \\
\text { metropolitan level, a model } \\
\text { adapted from Economy-Wide } \\
\text { MFA, was applied, i.e. the UMAn } \\
\text { Model. }\end{array}$ & - \\
\hline Imputations & $\begin{array}{l}\text { Errors associated with } \\
\text { imputations can occur when non } \\
\text { mass data is converted into mass } \\
\text { weight or when data is } \\
\text { downscaled. }\end{array}$ & $\begin{array}{l}\text { Whenever possible, and when } \\
\text { imputations were made, the data } \\
\text { was cross-checked against other } \\
\text { similar data. }\end{array}$ & C, D \\
\hline Mistakes & $\begin{array}{l}\text { Mistakes can occur when a MFA is } \\
\text { performed. }\end{array}$ & - & - \\
\hline
\end{tabular}

To assess the uncertainty in the MFA indicators, the previous types of errors had to be aggregated. The measurement errors include the errors described in statistical reports for 
several used databases (Type A). This is the case of Road transport data, collected from a report that has information on measurement errors as a $95 \%$ of Confidence Interval (normaly distributed). Measurement errors also include errors for databases that were provided by Expert Judgment (Type B), as for instance Water transport data, from which measurement errors were assigned by a statistical expert that provided the data. There are also imputation errors associated with the imputation of missing values (Type C). Finally, for lack of information about errors in databases, it was assumed the maximum error of similar databases (Type D), as for instance rail transport data from which uncertainty was impossible to assess.

\section{$<$ heading level 2> Propagation of errors in MFA Results}

In this article, we will concentrate on studying the effect that database measurement errors and imputations have on the value of MFA indicators. Our goal is to incorporate the evaluation of errors associated with measurement into calculation of DMI, DPO and DMC in a descriptive MFA case study. MFA indicators are linear combinations of data. These, in turn, are calculated by summing together the amount of tonnes of products. The measurements of these are imprecise, and may be more suitably described by a probabilistic distribution. Since we treat measurements as random variables, the indicators themselves are random with an associated distribution. In order to evaluate uncertainty in calculation of indicators, an estimate of this distribution is needed. Two common and straightforward methods to obtain it have been suggested in the literature: Gauss's law of error propagation (equation 2) and Monte Carlo Simulations (Baccini and Bader, 1996; Brunner and Rechberger 2004; Laner et al. 2014). For both methods, the statistical distribution of the input variables has to be known. Gaussian error propagation can only be used under the assumption that the measurement errors are independent. Monte Carlo Simulation is a numerical technique used to sample probability distribution.

The data used in this study originates from different institutions with different ways of accounting the databases measurement errors. The databases collected from the same institution are based on different surveys, as for instance agriculture production and International trade data from SCB. Therefore it is reasonable to assume that the variables are independent from each other. The collected measurements available in reports are reported to follow a normal distribution (e.g.: agriculture production, road transport data). Thus, in this article, we will use the first approach to estimate the amount of uncertainty associated with the calculation of MFA indicators. Assuming that the individual measurements are normally distributed with expectation $\theta_{i}$ and standard deviation $\sigma_{i}$, with the unit of measurement being tonnes. Then, the indicators, which are linear combinations of these, will also be normally distributed with expected value $\theta=\theta_{1}+\ldots+\theta_{n}$ and standard deviation given in Equation 5 . Equation 6 shows how the standard deviation of DMI indicator at Region level can be calculated.

Equation 5:

$$
\begin{aligned}
& \sigma_{a+b}=\sqrt{{\sigma_{a}{ }^{2}+{\sigma_{b}}^{2}}^{2}} \\
& \text { where } a, b \text { are physical idenpendent variables, and } \sigma_{a}, \sigma_{b}, \sigma_{a+b} \text { the standard deviations }
\end{aligned}
$$

Equation 6: 


$$
\begin{aligned}
& \sigma_{D M I \text { Region }}=\sqrt{\sigma_{\text {Road Nat. Imp. }}{ }^{2}+\sigma_{\text {Road Int. Imp. }}{ }^{2}+\sigma_{\text {Water Int. Imp. }}{ }^{2}+\sigma_{\text {Water Int. Imp. }}{ }^{2}+{\sigma_{n}}^{2} \ldots} \\
& \text { where } \sigma_{n} \text { are the standard deviations in tonnes from physical idenpendent variables, } \\
& \text { includinding all the imports by means of transport, and the Domestic Extraction }
\end{aligned}
$$

However, in reality $\theta i$ and $\sigma i$ are not known, and have to be estimated from the data. To obtain such estimates, data measurements errors were requested whenever a database was collected. In some cases, this information was not available, and therefore the uncertainty in the measurements was assessed by statistical expert's judgements, a common practice in MFA studies. This assessment usually takes the form of an interval that, according to the experts, covers the true value of $\theta i$ with great probability. For instance, an expert could state "in water transport, measurement errors are never more than 5 percent". It was decided to ask the experts simply to produce a maximum interval without specifying the degree of confidence. This was done based on the study done Teigen and Jorgensen (2005), in which is concluded that when people produce an uncertainty interval, it is not primarily based on probability considerations. According to the same authors, by using this approach, experts tend to give wider intervals, and therefore the associated overconfidence can also be reduced. In order to access the uncertainty, when measurement errors were based in expert's judgements, the $\theta \mathrm{i}$ and $\sigma \mathrm{i}$ had to be estimated, assuming that the given intervals will have a confidence interval of $99 \%$.

In some cases, the databases measurements errors were given in an interval of confidence of $95 \%$, following a normal distribution. For these cases, and in order to account the standard deviation, the measurement errors were assumed to represent 2 standard deviations, as is shown in the Equation 7:

Equation 7:

$$
\begin{gathered}
\text { Road National Imports Stockholm Region }=2,022,118 \mp 343,760 \text { tonnes } \\
\text { \%Road National Imports } \text { Stockholm Region. }=\frac{343,760}{2} \text { tonnes }=171,880 \text { tonnes }
\end{gathered}
$$

These two ways of assessing uncertainty, result in two different approaches to obtaining estimates of $\theta_{i}$ and $\sigma_{i}$, both of which are explained in detailed in Supplementary Material Section 1.

From now on, we will represent the uncertainty (both in individual measurements and in the calculated indicators) as an interval of the form estimated $\mu+$ estimated $\sigma_{i}$, where estimated $\mu$ and estimated $\sigma$ are obtained as described above and in Supplementary Material Section 1. This interval is symmetric (on the tonnes scale) and has the property that, if the measurement or indicator indeed came from the estimated distribution, its value would be within this interval with probability 0.68 . However, this interval will be represented in percentage, rather than in tonnes. This is done to allow a comparison of the MFA indicators at different spatial scales. The percentage is calculated by dividing estimated $\sigma$ by estimated $\mu$, which will give us an interval on the form [1+-estimated $\sigma /$ estimated $\mu] * 100 \%$. 
As an example for calculation of uncertainty intervals, both on the tonnes scale and on the percentage scale consider DMC. In the following Equation, the uncertainty associated with this indicator is calculated for Gothenburg in 2011:

Equation 8:

$$
\begin{gathered}
\text { DMI }_{\text {Gothenburg M.A. }}=46,122,233 \pm 934,797 \text { tonnes } \\
\text { EXPORTS }_{\text {Gothenburg M.A. }}=34,776,203 \pm 945,246 \text { tonnes } \\
\text { SD }_{\text {DMC Gothenburg M.A. }}=\sqrt{934,797^{2}+945,246^{2}}=1,329,412 \text { tonnes } \\
\text { DMC }_{\text {Gothenburg M.A. }}=11,346,030 \pm 1,329,412 \text { tonnes } \\
\quad{ }_{\text {ODMC }} \text { Gothenburg M.A. } \\
=\frac{1,329,412}{11,346,030}=11.72 \%
\end{gathered}
$$

If the distribution of the used databases is not known, the maximum intervals approach can be used, by adding the lowest and highest values within the intervals (Hansen and Lassen 2002). The results using this approach can be seen in Supplementary Material Section 2.

\section{$<$ heading level $1>$ Results and Discussion $<$ heading level 2> Data inputs}

According to the MFA methodology, two sets of data, domestic extraction and imports, were used for calculating the material flow Inputs (for details on the MFA indicators, see Rosado et al. 2014b). For the country scale, the data availability and quality was good. In particular, annual international trade statistics are collected in accordance with EU regulations, with measurement errors of 1-2\% (based on Expert Judgment), and available from the Swedish national statistics office (SCB). Domestic extraction is also available. However, imputations had to be made for data not traditionally covered by statistics offices, such as grazed biomass and used crop residues (see Supplementary Material tables 5-8 for a complete list of imputations made). In addition, conversion into mass weight was made for wood extraction and nurseries, using conversion factors from the Eurostat Compilation Guide 2012. Imputations were also necessary for agriculture production for urban areas, as was stated before.

Other domestic extraction was disaggregated in a way that allowed accounting at the metropolitan area and even municipality scale, the lowest spatial resolution available. For instance, the quantity of fish products was available by unloading port, and the extraction of construction minerals (sand, gravel and crushed stone) was available by municipality. Construction minerals are in fact the most important category of domestic extraction by weight and accounts for at least $50 \%$ of the total materials extracted in the studied metropolitan areas. These results are in line with the statement by Fisher-Kowalski and colleagues (2011), which said that construction minerals account for more than one third of the global material extraction. Consequently, the data measurement errors for the extraction of non-metallic minerals are very important when the total uncertainty in the amount of urban domestic extraction is evaluated. The non-metallic minerals data was available at municipal level, with measurement errors based on expert judgment. 
Data confidentiality was an issue only for agricultural production. To analyse the influence of the confidential data, the percentage of confidential data for all the NUT II Swedish Regions was calculated for certain products and compared to the total amount available for the country as a whole. The fraction of confidential data was found to be negligible; in 2011 it was $0.3 \%$ for apple production, $0.1 \%$ for broccoli and $1.1 \%$ for winter wheat production. Finer spatial resolution was associated with a higher probability of the data being confidential, due to a lower number of producing companies. This is in line with the comments by Hammer and colleagues (2003) that regional data confidentiality can be an issue when a specific product is only produced by a small number of firms.

Another issue relating to the data collection was the missing values for some years in the agricultural production data. This applied mostly to data from before 2000. For Sweden, 25.0\% of values were missing for the years 1996-1999, and 4\% between 2000 and 2012. For a number of collected databases, including sea water fishing and rail transport data, there was no information about data measurement errors.

As shown in Supplementary Material figure 2, the origin of the material flow Inputs depends on the scale studied. At country level, the majority of the material flow Inputs come from domestic extraction, which for all the studied years comprised more than $70 \%$ of the total material flow Inputs. For this reason, the uncertainty associated with the material flow Inputs indicator is mostly related to the domestic extraction, the extraction of minerals in particular, as this segment made up more than $65 \%$ of the domestic extraction in Sweden during the time period studied. In contrast, imports are the most important material flow Input for Stockholm Region and metropolitan areas. Due to this effect the data measurement errors of the regional and metropolitan transport statistics, used for accounting the intranational and international imports, are important when the total uncertainty in the regional material flow Inputs is calculated. It should be noted that the data errors measurement interval reported for the regional transport statistics, $3-14 \%$, is much higher than for the international trade data (1-2\%) used for country scale accounting.

Moreover, regional transport statistics (intranational and international: water, road, rail and air) have different reporting measurement errors. Air and water transport data is the most accurate, with $2 \%$ of reported measurement errors (Trafikverket and SCB), while a maximum measurement error of $14 \%$ has been reported for the road transport data (Trafikanalys). For rail transport, average measurement errors of $12 \%$ were assumed, as no information was available. As shown in Supplementary Material figure 3, each metropolitan area has different proportions of imports and exports of goods by transport mode. This means that the type of transport used has a significant impact on the uncertainty of the accounted flows. For instance, as Gothenburg has the largest harbour in the Nordic countries, its material flow Inputs are dominated by the water international trade transport (Business Region Göteborg $A B$ ). In general, for Stockholm Region and the metropolitan areas, the water and road transport combined always comprise over $85 \%$ of the total amount of goods carried, both in the imports and exports category, while the proportion of goods imported and exported by rail never exceeded $15 \%$. The air transport was responsible for the smallest share of the total amount of goods carried (less than $1 \%$ of the total). 
The water, road and air transport statistics were usually available at the resolution level of a port, airport or municipality. The railway data, on the other hand, was only available in the form of the amount of goods transported to and from Swedish NUT II Regions in 2010 (Eurostat data). For the remaining years, only data on the total amount of goods transported by train within Sweden, and exported to and from Sweden was available. National data was therefore used to impute the intranational and international imports and exports of goods registered in the Stockholm Region and metropolitan areas. The impact of this imputation on the MFA results is probably limited, as the proportion of goods imported and exported by train in 2010 (for which data was available) did not exceed $15 \%$.

The material flow Outputs account encompasses three sets of data: air emissions, waste disposal and dissipative flows (i.e. inorganic fertilizers, spread manure, pesticides, salt, sand and gravel). Again, data was easier to obtain at country scale than for the region and metropolitan areas. However, the material flow Outputs data was generally less complete than the material flow Input data. This is in line with the statement by Fischer-Kowalski and colleagues (2011) that material flow Input data is traditionally easier to collect.

Air emissions cover the $\mathrm{CO}_{2}$ emissions from both fossil fuels and biomass. In weight and according to Regional Development and Cooperation (RUS) data, the $\mathrm{CO}_{2}$ emissions in Sweden in 2011 amounted to $94.9 \%$ of the combined total of 26 different emissions measured. Based on this, the other emissions were neglected in this study. Data for the Stockholm Region and metropolitan areas were available by municipality for the years 2000 and $2005-2011$, and categorized by emission source. For the remaining years, imputations were made by applying the region's share of the emissions for the country as a whole, registered in the nearest year for which it was known, to the country scale statistics for each economic activities sector. Indeed, at every studied scale in Sweden air emissions account for more than $43 \%$ of the total material flow Outputs to Nature.

For the Stockholm Region and the metropolitan areas, data on urban waste generation was available at municipal level after 2007. For the earlier years, numbers were imputed based on per capita national values. The biggest information gap in the output to Nature was the waste disposed by economic activity. As shown in Supplementary Material figure 4, for 2010 and at country scale, this data represents $19.5 \%$ of the total material flow Outputs to Nature.

To summarize, the main difference between MFA at the country and regional scales is the data availability (Browne et al. 2011; Hammer et al. 2003b; Hinterberger et al. 2003). The difficulties related to data collection at the regional scale in this study include: 1) data is spread among several institutions (e.g.: transport data); 2) confidentiality of data (e.g.: some crops in agriculture production); 3 ) data is available at a regional scale, but not at lower administrative boundaries (e.g.: agriculture production); 4) some data is only available at country scale (e.g.: air emissions). For the above reasons, data processing is necessary for urban MFAs.

\section{$<$ heading level 2> Imputations}

As stated before, two approaches were tested, to account agriculture production at Urban Level, by number of workers and arable land. In order to identify which of the two 
approaches caused the smallest errors, two imputations for the NUT III region based on the NUT II (a larger region) were made and the results compared to the real data that is available for the NUT III region (table 3). The approach that used the ratio of land area resulted in smaller differences in the interval $0.4-18.3 \%$ for the agricultural and $0.4-29.7 \%$ for the wood production respectively, for the 16-year study period. A correlation analyses between real values and the estimated values was done. Results show a $R^{2}=0.49$ (agricultural) and $R^{2}=0.86$ (wood production) when arable land approach was used and $R^{2}=0.60$ (agricultural) and $R^{2}=0.18$ (wood production) when the number of workers was used (see Supplementary Material Figure 5).

Table 3 - Differences for different imputation methods for agriculture production and forestry extraction

\begin{tabular}{|c|c|c|c|c|c|c|c|c|c|c|c|c|c|c|c|c|}
\hline Employees approach & 1996 & 1997 & 1998 & 1999 & 2000 & 2001 & 2002 & 2003 & 2004 & 2005 & 2006 & 2007 & 2008 & 2009 & 2010 & 201 \\
\hline Agricultural production & $0.4 \%$ & $3.9 \%$ & $1.4 \%$ & $19.8 \%$ & $0.5 \%$ & $6.2 \%$ & $5.5 \%$ & $13.9 \%$ & $1.5 \%$ & $13.9 \%$ & $13.0 \%$ & $0.0 \%$ & $4.3 \%$ & $6.9 \%$ & $7.1 \%$ & 4.3 \\
\hline Forestry & $14.2 \%$ & $14.5 \%$ & $9.0 \%$ & $3.4 \%$ & $27.9 \%$ & $1.5 \%$ & $35.5 \%$ & $23.8 \%$ & $5.6 \%$ & $27.5 \%$ & $51.0 \%$ & $16.8 \%$ & $13.8 \%$ & $11.5 \%$ & $34.2 \%$ & $\overline{26.0}$ \\
\hline Land area approach & 1996 & 1997 & 1998 & 1999 & 2000 & 2001 & 2002 & 2003 & 2004 & 2005 & 2006 & 2007 & 2008 & 2009 & 2010 & 201 \\
\hline Agricultural production & $7.8 \%$ & $1.5 \%$ & $12.8 \%$ & $18.3 \%$ & $2.8 \%$ & $4.9 \%$ & $3.4 \%$ & $10.9 \%$ & $2.0 \%$ & $12.1 \%$ & $9.9 \%$ & $0.4 \%$ & $4.9 \%$ & $7.3 \%$ & $5.9 \%$ & $4.3 !$ \\
\hline Forestry & $0.6 \%$ & $0.4 \%$ & $1.4 \%$ & $4.0 \%$ & $5.3 \%$ & $4.9 \%$ & $3.9 \%$ & $25.8 \%$ & $24.3 \%$ & $29.7 \%$ & $23.3 \%$ & $3.3 \%$ & $2.7 \%$ & $5.3 \%$ & $4.5 \%$ & $4.5 !$ \\
\hline
\end{tabular}

Some material flow Outputs had also to be imputed, such as waste disposal by economic sector (NACE classification) data. This was done based on the average waste disposed per worker per sector observed in the adjacent years, and the number of workers per economic sector during the imputed year. Such an approach resulted in a difference of $7 \%$, as identified by comparing the imputed figure for 2010 with real statistical data. Regarding the imputation of $\mathrm{CO}_{2}$, using the national amounts per year, and the share of the economic activities of each metropolitan area, the results show a $\mathrm{R}^{2}$ of 0.50 to Gothenburg Metropolitan Area, 0.96 to Malmo Metropolitan Area and 0.63 to Stockholm Region (see Supplementary Material Figure 6).

\section{uncertainty}

$<$ heading level 2> Evaluation if the effect of data measurement in MFA indicators

The effect that data measurement errors have on the MFA indicators was evaluated by considering these indicators to be random, and obtaining an estimate of the corresponding distributions as described in section Methods. The results regarding DMI indicator (see Supplementary Material table 9 for tabulate results), including the uncertainty intervals, are presented in figure 2 . As expected, the relative uncertainty associated with the country scale accounting is lower $(0.6-0.7 \%)$ than for the Stockholm Region (2.0-3.3\%) and metropolitan areas (2.0-5.3\%). There are two main reasons for this difference: 1 ) transport data at country level is based on international trade statistics, which has less relative uncertainty than the regional transport statistics used at the regional and metropolitan scale; 2) MFA at urban level aggregates uncertainties from more sets of data, since intranational and international imports per mode of transport have to be accounted for. 

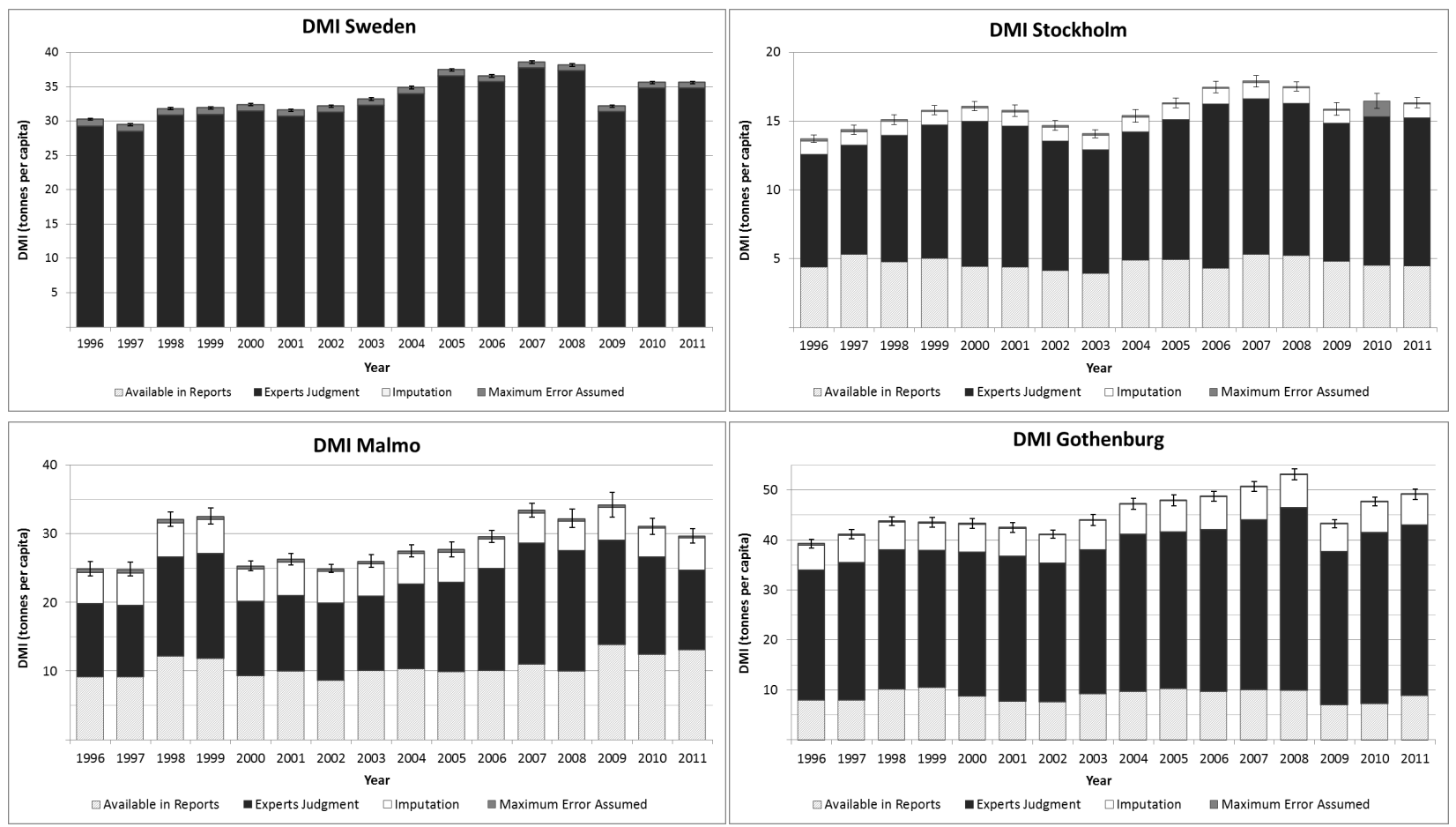

Figure 2 - Direct Material Flow Inputs at different scales and the associated standard deviations

The DMI MFA results for Malmo resulted in the largest relative uncertainty among the metropolitan areas. This is due to the fact that its agricultural production represents approximately $15 \%$ of the total material flow Inputs and also because the majority of the imports were done by road. For Gothenburg, the uncertainty is smaller, because the share of agricultural production is small $(<2 \%)$. Moreover, the majority of the imports to Gothenburg are by water-based modes of transport, which have lower uncertainty than road transports.

The uncertainty associated with the DPO (see Supplementary Material table 10 for tabulated results) at country scale accounting is lower $(2.1-2.8 \%)$ than for the Stockholm Region (3.3-5.0\%) and the metropolitan areas (2.2-3.6\%), as shown in figure 3. In general, the uncertainty of DPO depends in a large part from the uncertainty from the air emissions data (approximately 50\%), which after 2007 was collected at municipal level and has good quality. In this specific case there is one single variable (air emissions) with estimated variance much larger than the other ones in the sum. Therefore it contributes the most to the estimated variance of the DPO indicator. 

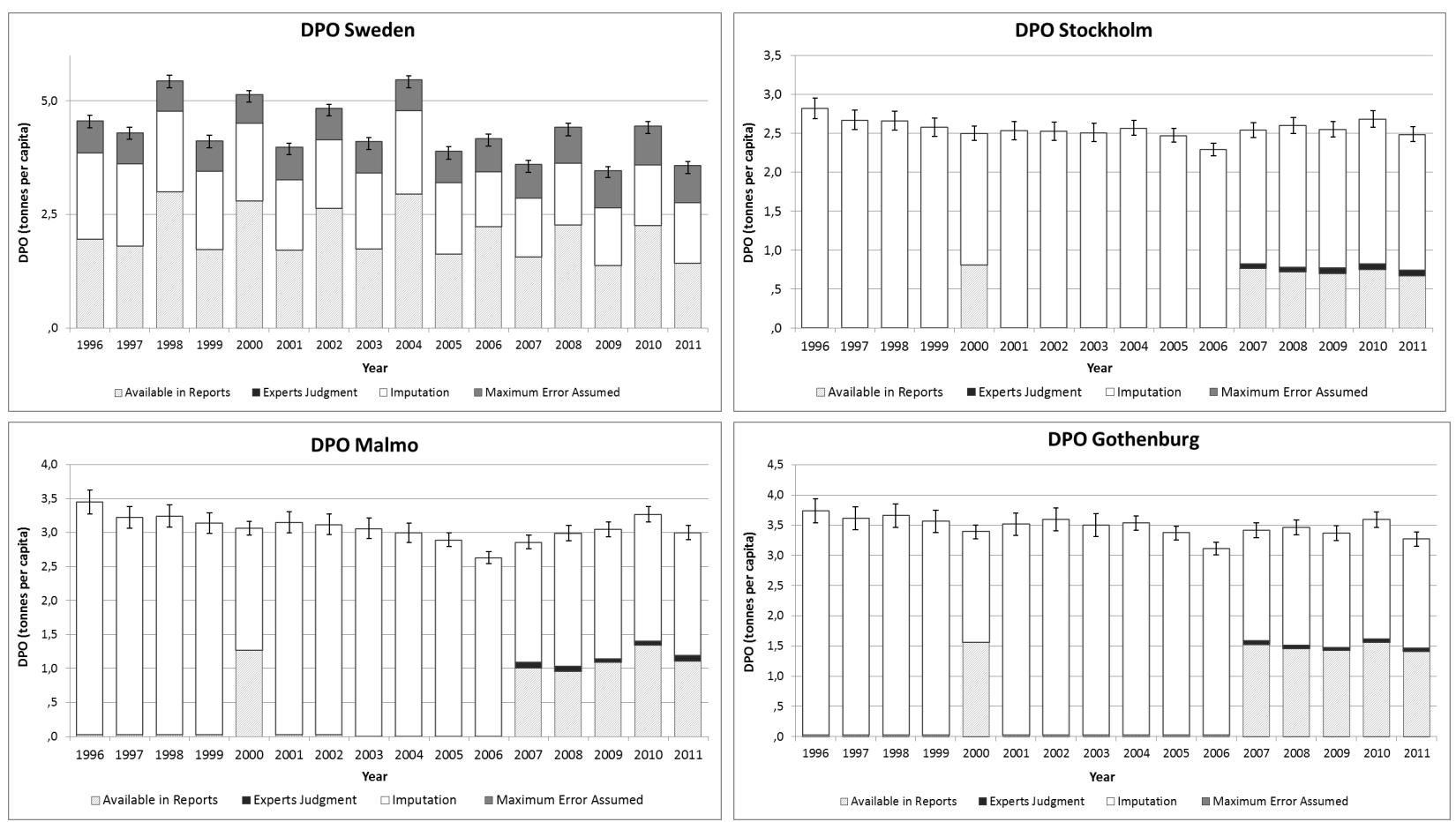

Figure 3 - Domestic Processed Output (DPO) at different scales and the associated standard deviations

The uncertainty associated with the DMC (see Supplementary Material table 11 for tabulated results) was evaluated by combining the estimated variations of the DMI and the exports, using equation 1 . For the country scale, the relative uncertainty was low, due to the good quality of the international trade data (a maximum of $1.9 \%$ ). The uncertainties for the Stockholm Region (3.8-8.6\%) and for the metropolitan areas (3.8-22.6\%) are higher due to the high relative errors regional transport data, on which the export data are based (see Supplementary Material table 12 for tabulated results). The DMC uncertainty depends on the ratio between Imports and Consumption (DMC) registered in each Region. Regions with high ratio as for instance Gothenburg (3.2 to 5.5) have higher uncertainty in the DMC (with uncertainty intervals on the percentage scale between 11.4-22.6). The lower the ratio, the less uncertainty is found. Malmo has a ratio that varies from 1.1 to 2.1 (7.0-19.5 \%), and Stockholm Region varies from 0.9 to $1.3(3.8-8.6 \%)$. This is even more evident at the country level, where the ratio varies from 0.4 to 0.5 , and the width of the uncertainty intervals associated with DMC is between 1.0 and $1.2 \%$.

\section{<heading level 2> Dependence of the MFA indicators on the errors types}

As it can be seen in Figure 2, the imputed data represents a maximum of $19 \%$ for Metropolitan Areas and 7\% for Region, of the total weight of the DMI indicator. Similar values were found for Exports data, in which imputations represent a maximum of $8 \%$ (Stockholm Region) and $14 \%$ (metropolitan areas). Therefore, and for the specific case of DMI indicator and DMC indicator we may reasonably assume that the error originating from imputation has a relatively small impact on the results (maximum of $19 \%$ for the DMI indicator and $14 \%$ for the Exports), and especially if the study Region encompasses a complete NUT II Region. The material 
flow Outputs and particular the DPO indicator (Figure 4) is completely based on imputed data, particularly for the years before 2005. For those years, $99 \%$ of the DPO values had to be imputed from National level. After 2004 and also in 2000, data for fossil fuels origin $\mathrm{CO}_{2}$ emissions was available at municipal level, as well as urban waste. Also urban waste became available at municipal level after 2007. Therefore after 2007 a maximum of $70 \%$ and a minimum of $54 \%$ of imputed data can be found for both Stockholm Region and Metropolitan Areas. Therefore, the DPO indicator accounted for Metropolitan Areas and Regions should be interpreted with caution.

The uncertainty in the DMI indicator is mostly based on errors from expert judgement evaluation, particularly at a country level, in which it represents always more than $96 \%$ of the indicator weight. For region it represents between 55-68\% and for metropolitan areas between $39-72 \%$. A sensitivity analysis is present in supplementary information (Section 3 ) showing the results when $90 \%$ of confidence that the true value falls within the expert-opinion range and in the imputations error is considered, instead of the $99 \%$ used in the article.

Errors Available in Report are still a small share of all the MFA indicators, with a maximum of $44 \%$ in the DMI indicator for the Metropolitan Areas. The share of this type of errors in the indicators should be increased, since this is the most reliable source of uncertainty.
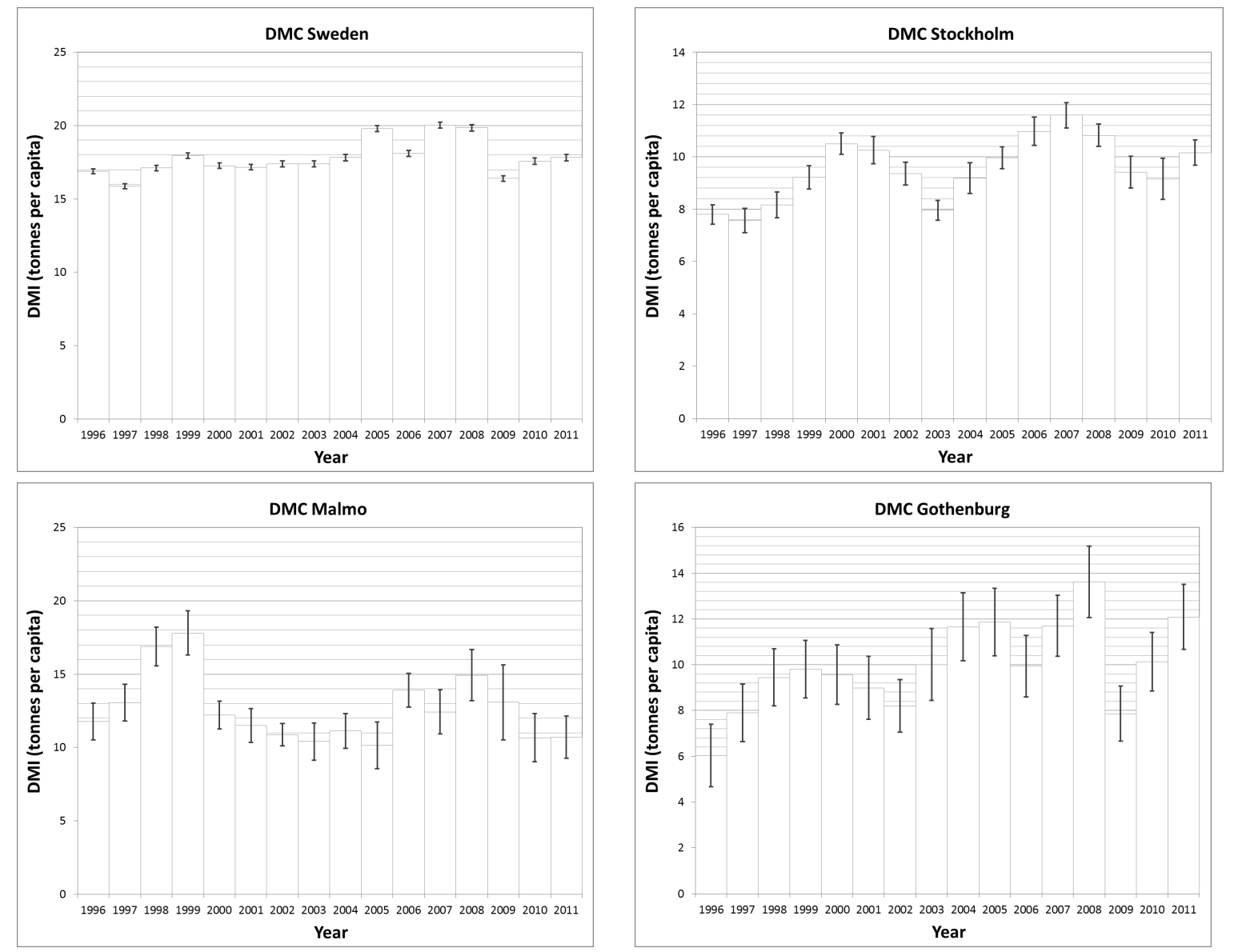


\section{Figure 4 - Domestic Material Consumption (DMC) at different scales and the associated standard deviations}

\section{$<$ heading level 2> Closing the Material Balance}

Since MFA is based on a material balance, all the accounted material flow Inputs must equal the Output plus the Net Addition to Stock (NAS). In most MFA case studies, the NAS is calculated by subtracting the DPO and the Exports from the DMI (e.g., Browne et al. 2011; Barles 2007; Scasny et al. 2003) or it is not taken into account at all (e.g., Statistics Netherlands 2009; Carlsson et al. 2006). When the UMAn model is used, the NAS is accounted based on the calculated DMC (Rosado et al. 2014a). Therefore, and with all the flows taken into account (Rosado et al. 2014b), it is possible to calculate the model's differences by producing a final material balance for the studied region, which corresponds to the difference between the DMI and the DPO plus the Exports and the accounted NAS. For the Swedish Metropolitan Areas case study, the previous differences vary between $0.2-12.3 \%$, as shown in table 4.

Table 4 - UMAn Model Differences [DMI - (Exports + DPO + Stock)]

\begin{tabular}{|c|c|c|c|c|c|c|c|c|c|c|c|c|c|c|c|c|}
\hline Region / Year & 1996 & 1997 & 1998 & 1999 & 2000 & 2001 & 2002 & 2003 & 2004 & 2005 & 2006 & 2007 & 2008 & 2009 & 2010 & 2011 \\
\hline Malmo & $7.7 \%$ & $10.7 \%$ & $8.8 \%$ & $9.3 \%$ & $9.1 \%$ & $12.3 \%$ & $8.5 \%$ & $5.4 \%$ & $7.9 \%$ & $6.8 \%$ & $9.5 \%$ & $1.7 \%$ & $6.7 \%$ & $5.6 \%$ & $2.4 \%$ & $1.9 \%$ \\
\hline Gothenburg & $5.2 \%$ & $0.7 \%$ & $0.6 \%$ & $0.5 \%$ & $1.0 \%$ & $0.9 \%$ & $2.6 \%$ & $0.9 \%$ & $1.6 \%$ & $2.1 \%$ & $0.6 \%$ & $0.3 \%$ & $2.0 \%$ & $3.0 \%$ & $2.1 \%$ & $0.6 \%$ \\
\hline Stockholm & $2.0 \%$ & $0.4 \%$ & $0.6 \%$ & $1.0 \%$ & $3.1 \%$ & $1.5 \%$ & $2.4 \%$ & $0.2 \%$ & $2.2 \%$ & $3.1 \%$ & $1.8 \%$ & $1.2 \%$ & $0.8 \%$ & $3.7 \%$ & $3.9 \%$ & $2.4 \%$ \\
\hline
\end{tabular}

\section{<heading level $2>$ Limitations}

To be possible to account the uncertainty in MFA indicators, we are assuming independency between points, based on the fact that data was collected from different institutions that have different ways to gather data. More research it's necessary to better understand if the variables are independent from each other. It is also assumed that the uncertainty from the imputations has the maximum deviation registered, which is probably not entirely correct, but in order to account for uncertainty for the whole MFA, this was the best available option.

\section{$<$ heading level $1>$ Conclusions}

A comprehensive and rigorous quantitative analysis of the measurement errors and uncertainty associated with MFA data and results at different spatial scales was performed. This is was done, by applying a method that allows the reconciliation of different sources of uncertainty, in particular measurement errors available in reports, or based on expert judgements, imputation errors, or maximum errors. Results show that the DMI indicator is mostly dependent on errors based on expert judgements evaluation, and the DPO is mostly dependent on imputation errors. Errors available in reports are still limited, and the access to this type of errors should be improved, since they are the most reliable source of uncertainty.

The data availability generally decreased from the country level to the regional, and even further to the metropolitan areas, whilst the data measurement errors increased. In 
particular, the regional/urban scale MFA indicators have higher uncertainty due to: 1) data being spread between several institutions deploying different collection protocols and uncertainty assessment methods 2) confidential values 3) MFA at urban level aggregates uncertainties from more sets of data 4) MFA at urban levels is more dependent from imputation methods.

Confidential values are limited to the agriculture production, and therefore the values had to be imputed. Uncertainty evaluation of data collected by different institutions should become a standard procedure, since no general benchmark can be assumed and the data may have a major impact on the result, which is the case with the regional transport statistics.

Due to lower data availability at urban level, imputation methods that attempt to reconstruct the missing data from available data can be used, in particular, they may be employed if the data is missing at urban level, are accounted at other administrative scales. Several suitable imputation methods were presented. However, downscaling from the country scale to the urban scale should be carried with care, as regions exhibit very different resource consumption patterns.

Data for the material flow Outputs is less readily available and is more aggregated than the material flow Input data. In particular, the data on industrial waste generation by economic activity is fragmented, and had to be imputed even for the country scale. Also dissipative flows had to be imputed using per capita ratios. Therefore, material flow Outputs is highly dependent on imputation methods, especially at urban level.

The DMI indicator is characterized by the lowest uncertainty at all spatial scales, whilst the DMC by the highest with larger variations between the different spatial scales. The DMC uncertainty is highly dependent on the ratio between Imports and Consumption (DMC) registered in each Region. Regions with higher ratio are more susceptible to have larger uncertainty in the results

The uncertainty of MFA results would decrease with the availability of the national and regional level databases. In the specific case of Sweden, the data on freight transport by rail and on waste produced by economic activities at the regional and metropolitan level should be improved.

There is a need for development of a standardized methodology to account for the uncertainty in MFA studies to ensure high quality of the decision support information and allow for proper comparison between studies conducted by different authors in different countries, regions and metropolitan areas. In addition, further development of imputation methods for data requiring imputations should be pursued. This article contributes towards such a standardized method by introducing a novel approach to evaluate the impact of measurement errors in datasets with very few details on the measurement errors.

\section{<heading level 1> Acknowledgements}

This work was supported by the Built Environment Area of Advance, Chalmers University of Technology. 


\section{<heading level $1>$ References}

Baccini, P. and Bader, H.P. 1996, Regionaler Stoffhaushalt - Erfassung, Bewertung, Steuerung, Spektrum Akademischer Verlag GmbH, Heidelberg.

Barles, S. 2007. A material flow analysis of Paris and its region. Renewables in a changing Climate-Innovation in the Built Environment: 579-584.

Björklund, A. E. 2002. Survey of approaches to improve reliability in LCA. The International Journal of Life Cycle Assessment 7(2): 64-72.

Browne, D., B. O'Regan and R. Moles. 2011. Material flow accounting in an Irish cityregion 1992-2002. Journal of Cleaner Production 19(9): 967-976.

Brunner, P. H., Rechberger, H. (2004). Practical handbook of material flow analysis. The International Journal of Life Cycle Assessment, 9(5), 337-338.

Cañellas, S., A. C. González, I. Puig, D. Russi, C. Sendra, and A. Sojo. 2004. Material flow accounting of Spain. International Journal of Global Environmental Issues 4(4): 229-241.

Carlsson, A., A. Wadeskog, V. Palm and F. Kanlén. 2006. Material Flow Accounts and. Policy. Data for Sweden 2004. Environmental Accounts, Statistics Sweden. www.scb.se/statistik/_publikationer/MI1301_2004A01_BR_MIFT0701.pdf. Accessed 15 December 2013.

Danius, L. 2002. Data uncertainties in material flow analysis: local case study and literature survey. Licentiate Thesis, Royal Institute of Technology, Stockholm, Sweden.

Danius, L. and F. Burström. 2001. Regional material flow analysis and data uncertainties: can the results be trusted. Proceedings of 15 th International Symposium on Informatics for Environmental Protection, Zurich, Switzerland.

Eurostat. 2001. Economy-wide material flow accounts and derived indicators: A methodological guide. Luxembourg : Eurostat, European Commission, Office for Official Publications of the European Communities.

Fischer-Kowalski, M., F. Krausmann, S. Giljum, S. Lutter, A. Mayer, S. Bringezu, Y. Moriguchi, H. Schutz, H. Schandl, and H.Weisz. 2011. Methodology and indicators of economywide material flow accounting: State of the art and reliability across sources. Journal of Industrial Ecology. 15(6): 855-876.

Gottschalk, F., R. W. Scholz, and B. Nowack. 2010. Probabilistic material flow modeling for assessing the environmental exposure to compounds: Methodology and an application to engineered nano-TiO2 particles. Environmental Modelling \& Software 25(3): 320-332.

Hair, J. F., W. C Black, R. E. Anderson and R. L. Tatham, 1998. Multivariate data analysis.

Hammer, M., S. Giljum, and F. Hinterberger. 2003a. Material flow analysis of the city of Hamburg: Preliminary results. Paper presented at the workshop Quo vadis MFA? Material Flow 
Analysis-Where Do We Go? Issues, Trends and Perspectives of Research for Sustainable Resource Use, 9-10 October, Wuppertal, Germany.

Hammer, M., S. Giljum, S. Bargigli and F.Hinterberger. 2003b. Material Flow Analysis on the Regional Level: Questions, Problems, Solutions. Working Paper No. 2, Hamburg, Germany.

Hansen, E. and Lassen, C. 1998. A product composition database for material management: application for priority setting and substance flow analysis of aluminium in Denmark. In Ecologizing Societal Metabolism. Designing Scenarios for Sustainable Materials Management. CML report 148. Leiden University, Centre of Environmental Science, Leiden.

Hansen, E. and C. Lassen. 2002. Experience with the Use of Substance Flow Analysis in Denmark. Journal of Industrial Ecology, 6: 201-219

Hedbrant, J. and L. Sörme. 2001. Data vagueness and uncertainties in urban heavy-metal data collection. Water, Air, \& Soil Pollution: Focus 1(3): 43-53.

Hinterberger, F., S. Giljum, and M. Hammer. 2003. Material Flow Accounting and Analysis (MFA). A valuable tool for analyses of Society-Nature interrelationships. Sustainable Europe Research Institute (SERI) Background Paper, Nr. 2, August 2003.

Huybrechts, D., R. Berloznik, G. Wouters, J.-Y. Marion, G. Valenduc and P. Vendramin. 1996. The role of ecobalances in environmental decision-making. Journal of Cleaner Production 4(2): 111-119.

Kalmykova, Y., Rosado, L., Patrício, J. (2014) Trends in urban metabolism 1996-2011. Submitted for publication.

Kalmykova, Y., R. Harder, H. Borgestedt and I. Svanäng. 2012. Pathways and management of phosphorus in urban areas. Journal of Industrial Ecology 16(6): 928-939.

Kennedy, C., S. Pincetl and P. Bunje. 2011. The study of urban metabolism and its applications to urban planning and design. Environmental pollution 159(8): 1965-1973.

Laner, D., Rechberger, H., \& Astrup, T. (2014). Systematic Evaluation of Uncertainty in Material Flow Analysis. Journal of Industrial Ecology.

Lindqvist, A. 2002. Substance flow analysis for Environmental Management in Local Authorities - method development and context. Ph.D. thesis, Linköping Studies in Science and Technology, dissertation no 741. Environmental technique and management, Department of physics and measurement technology, Linköping University, Sweden.

Matthews, E., C. Amann, S. Bringezu, M. Fischer-Kowalski,W. Huttler, R. Kleijn, Y. Moriguchi, C. Ottke, E. Rodenburg, D. Rogich, H. Schandl, H. Schutz, E.v.d. Voet, and H. Weisz. 2000. The weight of nations: Material outflows from industrial economies. Washington, DC: World Resources Institute. 
$\begin{array}{llll}\text { Naturvårdsverket, } & 2012 . & \text { Avfall } & \text { i }\end{array}$ http://www.naturvardsverket.se/Nerladdningssida/?fileType=pdf\&pid=3829\&downloadUrl=/Do cuments/publikationer6400/978-91-620-6520-1.pdf. Accessed 8 April 2014.

Niza, S., L. Rosado, and P. Ferrão. 2009. Urban metabolism: Methodological advances in urban material flow accounting based on the Lisbon case. Journal of Industrial Ecology 13(3): 384-405.

OECD. 2008. Measuring material flows and resource productivity: Volume 1. The OECD guide. Paris : OECD.

Rosado, L., S. Niza and P. Ferrão. 2014a. A Material Flow Accounting Case Study of the Lisbon Metropolitan Area using the Urban Metabolism Analyst Model. Journal of Industrial Ecology. 16 (1): 84-101.

Rosado, L., Y. Kalmykova and J. Patrício. 2014b. Establishing differences and similarities for urban typologies in Sweden using MFA indicators to describe urban metabolism properties. Submitted for publication.

Ščasný, M., J. Kovanda and T. Hák. 2003. Material flow accounts, balances and derived indicators for the Czech Republic during the 1990s: results and recommendations for methodological improvements. Ecological Economics 45(1): 41-57.

Statistics Austria. 2009. Standard documentation Meta information (Definitions, explanations, methods, quality) on the Material Flow Accounts. http://www.cso.ie/en/media/csoie/surveysandmethodologies/surveys/industry/documents/pdf docs/QAll_quality_report2013.pdf. Accessed 12 November 2013.

Statistics Finland. 2010. Economy-wide Material Flow Accounts with Hidden Flows for Finland: 1945-2008. http://www.stat.fi/tup/julkaisut/tiedostot/isbn_978-952-244-233-8.pdf. Accessed 3 December 2013.

Statistics Netherlands. 2009. Material flow accounts in the Netherlands, time series 1996-2006. http://www.cbs.nl/NR/rdonlyres/D867533E-9F99-4E35-98DB504F4DACE57D/0/2009MFANetherlands.pdf . Accessed 6 November 2013.

Teigen, K. H., \& Jørgensen, M. (2005). When 90\% confidence intervals are $50 \%$ certain: On the credibility of credible intervals. Applied Cognitive Psychology, 19(4), 455-475.

\section{$<$ HEADING LEVEL 1> About the Authors}

João Patrício is a researcher, Yuliya Kalmykova is Associate Professor, Leonardo Rosado and Vera Lisovskaja are postdoctoral researchers, , all at Chalmers University of Technology, Sweden. 